\title{
Modification of micro-channel filling flow by poly(dimethylsiloxane) surface functionalization with fluorine-Substituted aminonaphthols
}

\author{
G. Cortese ${ }^{\mathrm{a}}$, F. Martina ${ }^{\mathrm{a}}$, G. Vasapollo $^{\mathrm{a}}$, R. Cingolani ${ }^{\mathrm{b}}$, G. Gigli $^{\mathrm{a}, \mathrm{b}}$, G. Ciccarella $^{\mathrm{a}, \mathrm{b}, *}$ \\ a Università del Salento, Dipartimento di Ingegneria dell'Innovazione, via Arnesano, I-73100, Lecce, Italy \\ ${ }^{\mathrm{b}}$ National Nanotechnology Laboratory (NNL) of CNR, INFM, Distretto Tecnologico ISUFI, via Arnesano, I-73100, Lecce, Italy
}

\section{A R T I C L E I N F O}

\section{Article history:}

Received 30 April 2009

Received in revised form 19 November 2009

Accepted 20 November 2009

Available online 1 December 2009

\section{Keywords:}

Microfluidics

Poly(dimethylsiloxane)

Surface functionalization

Aminonaphthols

Fluorine groups

\begin{abstract}
A B S T R A C T
Microfluidics based on the capillarity-induced filling of elastomeric channels by a suitable liquid or solution represents a useful route for realizing portable diagnostic devices designed without additional mechanical or electrical micropumps. In this study, an elastomeric mold made of poly(dimethylsiloxane) (PDMS), containing relief patterns placed in intimate contact with a silicon substrate, is utilized to create a continuous network of rectangular micro-channels for the motion of water fluid. The immobilization on activated PDMS surface of suitable functional molecules such as hydrophilic and hydrophobic fluorine-containing aminonaphthols, obtained through a straightforward and versatile synthetic procedure, allowed us to modulate PDMS surface properties depending on the structural characteristics of the employed derivative. In this context, the incorporation of fluorine groups is important for improving biocompatibility of the resulting device, providing surfaces that could be chemically and biologically inert as well as resistant to surface adhesion phenomena. The functionalization from liquid phase of PDMS replicas, involving a covalent derivatization via silanization reaction of the above mentioned compounds to an oxidized PDMS surface, resulted in a successful modification of microfluidic motion of water in rectangular capillaries, moreover contact angle values evidence also how wettability of PDMS films could be modulated, with the fluorinated aminonaphthols fuctionalized PDMS exhibiting higher contact angles.
\end{abstract}

(C) 2009 Elsevier B.V. All rights reserved.

\section{Introduction}

Microfabrication is essential to modern science and technology. Miniaturization and integration of a range of devices result in portability, reduction in time, costs, reagents, sample size and power consumption [1]. Furthermore, improvements in detection limits and a series of other new functions are also observed. In particular the possibility to implement mixers, diluters, and valves as components of a PDMS-based microfluidic circuit opens new perspectives for lab-on-chip applications such as bioassays and chemical sensors. This is possible mainly having the capability of modulating the filling flow of liquids within micro-channels by adopting the consolidated microfabrication technology.

The flow of a liquid in micro-channels is a thermodynamically driven capillary process, explained in terms of interfacial free energy between solid/vapour and solid/liquid interfaces. It occurs because of a pressure difference between two hydraulically connected regions of the liquid mass, the flow direction resulting

\footnotetext{
* Corresponding author at: Università del Salento, Dipartimento di Ingegneria dell'Innovazione, via Arnesano, I-73100, Lecce. Italy.Tel.: +390832 298233.

E-mail address: giuseppe.ciccarella@unisalento.it (G. Ciccarella).
}

from the decreasing of the pressure [2]. A system based on capillary action as driving force is suitable for portable diagnostic devices designed without additional mechanical or electrical micropumps [3].

Microfluidics based on the capillarity-induced filling of elastomeric channels by a suitable liquid or solution represents a very efficient method for patterning biomolecules and for the selective delivery of proteins from aqueous solutions, such as blood and saliva [4-6]. However, since the filling process depends on the interfacial free energies of micro-channel walls, there are several requirements for a successful patterning of such bio-derivatives $[7,8]$ : the micro-channels have to be sufficiently hydrophilic to promote filling by capillary action and at the same time, they should possess protein repellent surfaces, in order to prevent any loss of proteins to micro-channels walls. Therefore, since water motion strongly depends on the channel walls conditions, the wetting of solid surfaces by the liquid can be controlled by varying the interfacial free energies of one wall and/or all walls of the micro-channels.

In general, the filling rate of the fluidic channels is proportional to the reciprocal length of the capillary, $z$ : $d z / d t=R \gamma \cos \theta / 4 \eta z$, where $\eta, R, \gamma$, and $\theta$ indicate the liquid viscosity, the radius of the capillary, the liquid-vapour interfacial free energy of the fluid and 
the contact angle between the liquid and the surface of the capillary, respectively. $\theta$, whose cosine is proportional to the difference between the solid-liquid and the solid-vapour interfacial energies, determines whether the filling process is thermodynamically favoured, i.e., if the channels can be wetted by water $(\cos \theta>0)$ or not $(\cos \theta<0)$. Filling rate of channels can be influenced by geometrical factors [9] $(R$ and $z$ ) but also by suitable derivatizations of the involved surfaces, that can modify their wettability: the surface chemistry of PDMS can affect the applicability of this material in microfluidic processes involving pure water or water solutions. Among the numerous approaches used to change the PDMS surface characteristics [10], covalent modification has been providing successful results, since coating with physically and chemically stable derivatives allows the incorporation of suitable functional groups able to supply desiderable properties. In particular, a covalent modification of PDMS surface can be mainly performed through a photo-induced chemical reaction involving vinyl monomers or polymers [11-18] or by means of a silanization reaction [19-25] on activated PDMS surface. Unlike radiation induced surface derivatization, that necessitates the use of a vinyl compound, silanization allows the immobilization of a variety of materials useful for specific applications, thus resulting in improved microfluidic performances.

In the present work, a covalent modification of PDMS surface aimed to fulfil the above mentioned requirements is proposed: an elastomeric mold made of poly(dimethylsiloxane) (PDMS) containing relief patterns placed in intimate contact with a silicon substrate, is utilized to create a continuous network of rectangular micro-channels for the motion of water fluid (Figs. 1 and 5).

The approach described in this paper consists of a modulation of the filling rate of the rectangular capillaries by water. For this purpose, suitable derivatizations of PDMS surface were realized introducing a series of new synthesized molecules via silanization reaction onto activated micro-channel walls. In particular, the immobilization on activated PDMS surface [26-28] of hydrophilic and hydrophobic fluorine-containing aminonaphthols was performed and the resulting modifications in terms of surface wettability and channel's filling rate by water was evaluated: different surface properties were achieved depending on the structural characteristics of the employed derivative. In this context, it is reported [29] that incorporation of fluorine groups remarkably enhances hemocompatibility of the device, the presence of $\mathrm{C}-\mathrm{F}$ containing substituents leading to a more biocompatible surface. As well known, material biocompatibility is closely related to protein adsorption process, that may trigger

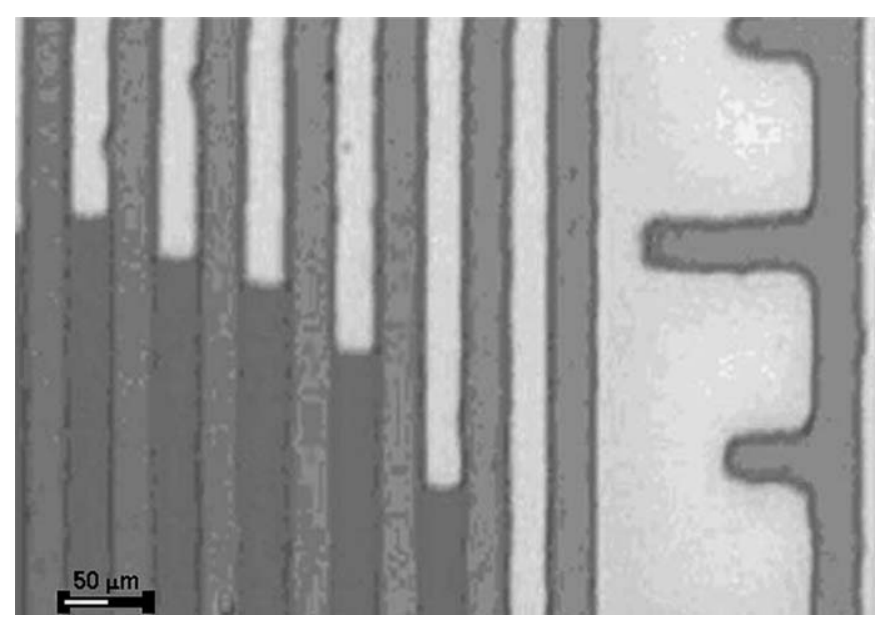

Fig. 1. Rectangular microfluidic channels for the capillary flow of water. the coagulation sequence [30]. The proposed study reports a PDMS surface modification by hydrophilic and fluorinated hydrophobic molecules, the last providing surfaces that could be chemically and biologically inert as well as resistant to surface adhesion phenomena involving biomolecular adsorption.

The preparation of such new aminoalcohols, also known as Betti bases [31-36], involved an inexpensive, efficient and versatile synthetic procedure involving (in a first step) a simple and straightforward condensation of 2-naphthol with an aldehyde and an amine. The successive $N$-methylation [32-33], in a strategy that involved the formation-cleavage of an oxazine ring, was employed to obtain tertiary aminonaphthols; their reaction with 3-triethoxysilylpropylisocyanate allowed the preparation of the direct precursors used in the surface modification of PDMS.

\section{Theoretical model for rectangular channel}

The thermodynamics of filling in capillaries [3] can be explained in terms of interfacial free energy and contact angle. A liquid fills in capillaries in order to minimize interfacial free energies of solid/ vapour and solid/liquid interfaces.

In the laminar regime, the rate of liquid flow in the capillary can be approximated using the Hagen-Poiselle equation, obtaining:

$\frac{d z}{d t}=\frac{\Delta P}{8 \mu z} R_{\mathrm{H}}^{2}$

where $R_{\mathrm{H}}$ is the hydraulic radius (the ratio between the volume and the surface area of the capillary, e.g., $w h z / 2(w+h) z$; in our model $R_{\mathrm{H}}$ is $0.62 \mu \mathrm{m}$, being $w=28.00 \mu \mathrm{m}$ and $\left.h=1.3 \mu \mathrm{m}\right), \mu$ the viscosity of the liquid (the viscosity value is $1.00 \times 10^{-3} \mathrm{~kg} /(\mathrm{m} \times \mathrm{s})$ at $20^{\circ} \mathrm{C}$ ), $z$ the length of the column of liquid, and $\Delta P$ (the pressure drop is represented by the capillary pressure for microfluidic channels of small dimensions, $<1 \mathrm{~mm}$ ) is the difference of pressure of the liquid mass between inside and outside the channel. $\Delta P$ can be calculated using the Laplace equation which, for a rectangular capillary of width $w$ and height $h$, approximately is:

$\Delta P=\gamma_{\mathrm{LG}}\left(\frac{\cos \theta_{\mathrm{Si}}+\cos \theta_{\mathrm{PDMS}}}{h}+\frac{2 \cos \theta_{\mathrm{PDMS}}}{w}\right)$

This expression [4] reveals that micro-channels filling is highly sensitive to the surface tension of the liquid, $\gamma_{\mathrm{LG}}$, and to the contact angles $\theta_{\mathrm{PDMS}}$ and $\theta_{\mathrm{si}}$ of the liquid with each of the walls of the micro-channel (Fig. 2).

The integration of Eq. (1) defines the displacement of the fluid filling the channel after a time $t$. Thus, the capillary dynamics for the length coordinate is described by a power law model

$z(t)=a+b t^{1 / 2}$

where

$b=\left[\frac{R_{\mathrm{H}}^{2} \gamma_{\mathrm{LG}}}{4 \mu}\left(\frac{\cos \theta_{\mathrm{Si}}+\cos \theta_{\mathrm{PDMS}}}{h}+\frac{2 \cos \theta_{\mathrm{PDMS}}}{w}\right)\right]^{1 / 2}$

and $a$ depends on operative measurement beginning. Eq. (3) is in agreement with the experimental data describing micro-channels

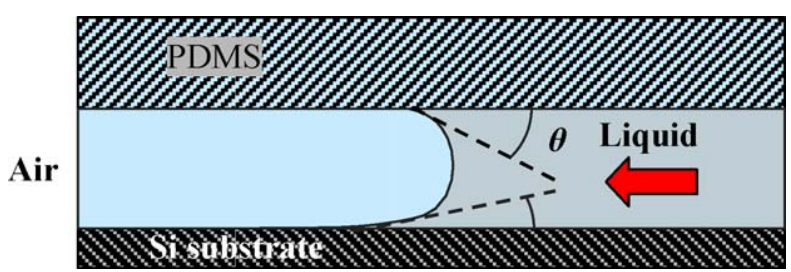

Fig. 2. A scheme for surface tension - driven flow of water in a rectangular microchannel. 
filling and the coefficient $b$, evaluated by a non-linear regression fit, $b_{\mu \mathrm{F}}$, can be compared with the one calculated using Eq. (4), $b_{\mathrm{CA}}$.

\section{Results and discussion}

\subsection{Synthesis of Betti-type aminonaphthols}

The main distinctive feature of Betti-type aminonaphthols $[31,32]$ is represented by a simple and high yield synthesis (the condensation of 2-naphthol with an aldehyde and an amine). The starting materials involved supply the surface modifiers adopted in the following experiments without significant amount of side products.

The first step proceeds through the formation of the Schiff base; in presence of 2-naphthol, a Mannich-like condensation takes place with the obtainment of the aminonaphthols 1-4. The subsequent reaction takes place by adding an excess of paraformaldehyde in ethanol solution, with the obtainment of the oxazine derivatives 1a-4a. The successive cleavage of oxazine ring under $\mathrm{N}$-methylation conditions (reduction by $\mathrm{NaBH}_{4}$ in THF and subsequent hydrolysis with trifluoroacetic acid) supplies the tertiary aminonaphthols $\mathbf{1 b}$ and $\mathbf{3 b} \mathbf{- 4 b}$. The reaction with 3(triethoxysilylpropyl-isocyanate) in the presence of triethylamine in dichloromethane solution [31] gives the surface modifiers 1c-4c (Scheme 1).

\subsection{Microfluidic tests and contact angle measurements}

Micro-channel water filling performances can be modulated by introducing variously substituted aminonaphthols on activated PDMS walls [31-33] (PDMS-OH). PDMS consists of repeating $\left(-\mathrm{OSi}\left(\mathrm{CH}_{3}\right)_{2}-\right)$ units which provide a hydrophobic, low interfacial energy, chemically inert surface. Even if the hydrophobic nature of the surface could be advantageous, however, in many diagnostic applications, it is necessary to make the surface of PDMS hydrophilic to improve wetting of aqueous solvents and ensure micro-channel filling by capillary action. Therefore, we covered the walls of PDMS micro-channels with polar $-\mathrm{OH}$ functionalities by exposure to $\mathrm{O}_{2}$ plasma [2628]. Subsequently, PDMS ${ }^{\text {ox }}$ was employed as base layer to chemically bind molecules having suitable characteristics (Scheme 2).

The structures of the new surface-modified samples PDMSc and PDMS1c-PDMS4c, obtained upon the first mentioned functionalization process, are reported in Chart 1.

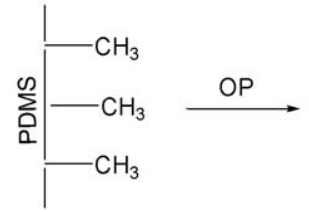

untreated PDMS
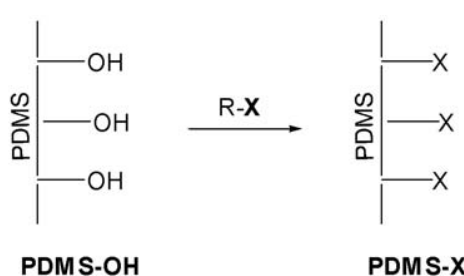

PDMS-X
Scheme 2. Step 1. PDMS ${ }^{\text {ox }}$ was obtained by a few minutes of $\mathrm{O}_{2}$ plasma. Step 2 . Incubation of PDMS ${ }^{\text {ox }}$ into dichloromethane solutions containing compounds $1 \mathrm{c}-\mathbf{4 c}$ resulted in surface-modified PDMS-X.

The immobilization of compounds $\mathbf{c}$ and $\mathbf{1 c}-\mathbf{4 c}$ was detected by FT-IR. The band at $2270 \mathrm{~cm}^{-1}$, typical of $-\mathrm{N}=\mathrm{C}=\mathrm{O}$ moiety, and the peaks at $2928 \mathrm{~cm}^{-1}$ and $2887 \mathrm{~cm}^{-1}$, corresponding to $-\mathrm{CH}-$ vibrations of the grafted isocyanate, are remarkable in IR spectrum of PDMSc.

Similarly, the functionalization process on PDMS1c-PDMS4c surfaces was evaluated. The band corresponding to carbamoyloxy group was evidenced at $1675 \mathrm{~cm}^{-1}$ (PDMS1c), $1723 \mathrm{~cm}^{-1}$ (PDMS2c), $1695 \mathrm{~cm}^{-1}$ and $1696 \mathrm{~cm}^{-1}$ (PDMS3c and PDMS4c respectively); The peaks around $1625 \mathrm{~cm}^{-1}, 1500 \mathrm{~cm}^{-1}$, $1370 \mathrm{~cm}^{-1}$ and $1250 \mathrm{~cm}^{-1}$, belonging to aminonaphtol moiety, are also remarkable.

Subsequently, the microfluidic behaviour of such surfaces towards water was evaluated. As a first step, 3-triethoxysylilpropyl isocyanate was covalently linked to PDMS-OH; the time to completely fill the capillaries by water (filling times refer to a $10 \mathrm{~mm}$ length) was decreased by a factor 1.5 (from 93 to $62 \mathrm{~s}$ ) with respect to untreated PDMS (Fig. 3 ). The decreasing of contact angle value (from $109^{\circ}$ to $83^{\circ}$ ) was in agreement with the microfluidic behaviour (Table 1 ).

The wettability of channels was further enhanced by linking on activated PDMS the tertiary aminonaphtol 1c; the time to fill the capillaries was decreased by a factor 2 respect to untreated PDMS (Table 1 ) and contact angle reached $79^{\circ}$. The basicity of the tertiary nitrogen in the structure of $\mathbf{1 c}$ makes the surface more hydrophilic. On the other hand, the compound $2 \mathrm{c}$, was found to be less polar because of the increasing of the contact angle $\left(94^{\circ}\right)$ and of the filling time (84 s). The more hindered nitrogen, belonging to the oxazine ring, is probably less available to interact with the water molecules. Fig. 4 reports the experimental $(z, t)$ curves describing the capillary motion of water in functionalised microchannels.

Indeed, oxidized PDMS can be exploited as a base layer to link a series of isocyanates bearing variously substituted amino-

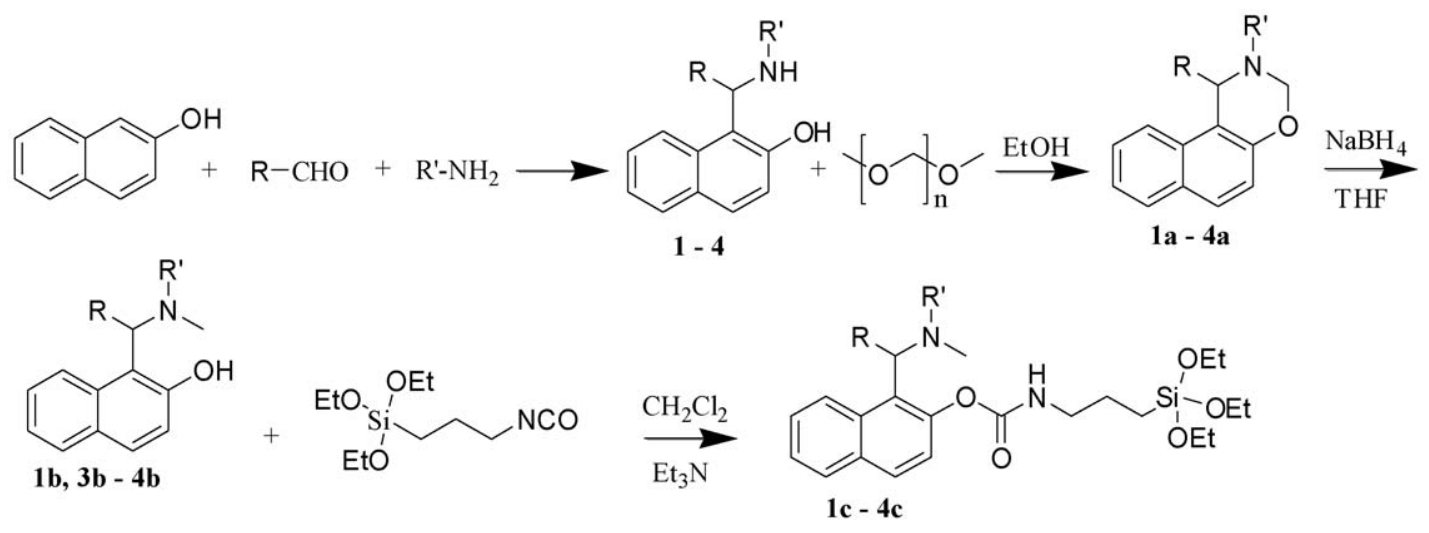

1: $\mathrm{R}=\mathrm{Ph}, \mathrm{R}^{\prime}=\mathrm{CH}_{3}-\mathrm{CH}-\mathrm{Ph} ; \mathbf{2}: \mathrm{R}=4 \mathrm{OHC}_{6} \mathrm{H}_{4}, \mathrm{R}^{\prime}=\mathrm{CH}_{3}-\mathrm{CH}-\mathrm{Ph}$;

3: $\mathrm{R}=2,3,4,5,6-\mathrm{C}_{6} \mathrm{~F}_{5}, \mathrm{R}^{\prime}=\mathrm{CH}_{3}-\mathrm{CH}-\mathrm{Ph} ; \mathbf{4}: \mathrm{R}=2,3,4,5,6-\mathrm{C}_{6} \mathrm{~F}_{5}, \mathrm{R}^{\prime}=3 \mathrm{~F}-\mathrm{C}_{6} \mathrm{H}_{4} \mathrm{CH}_{2}$. 

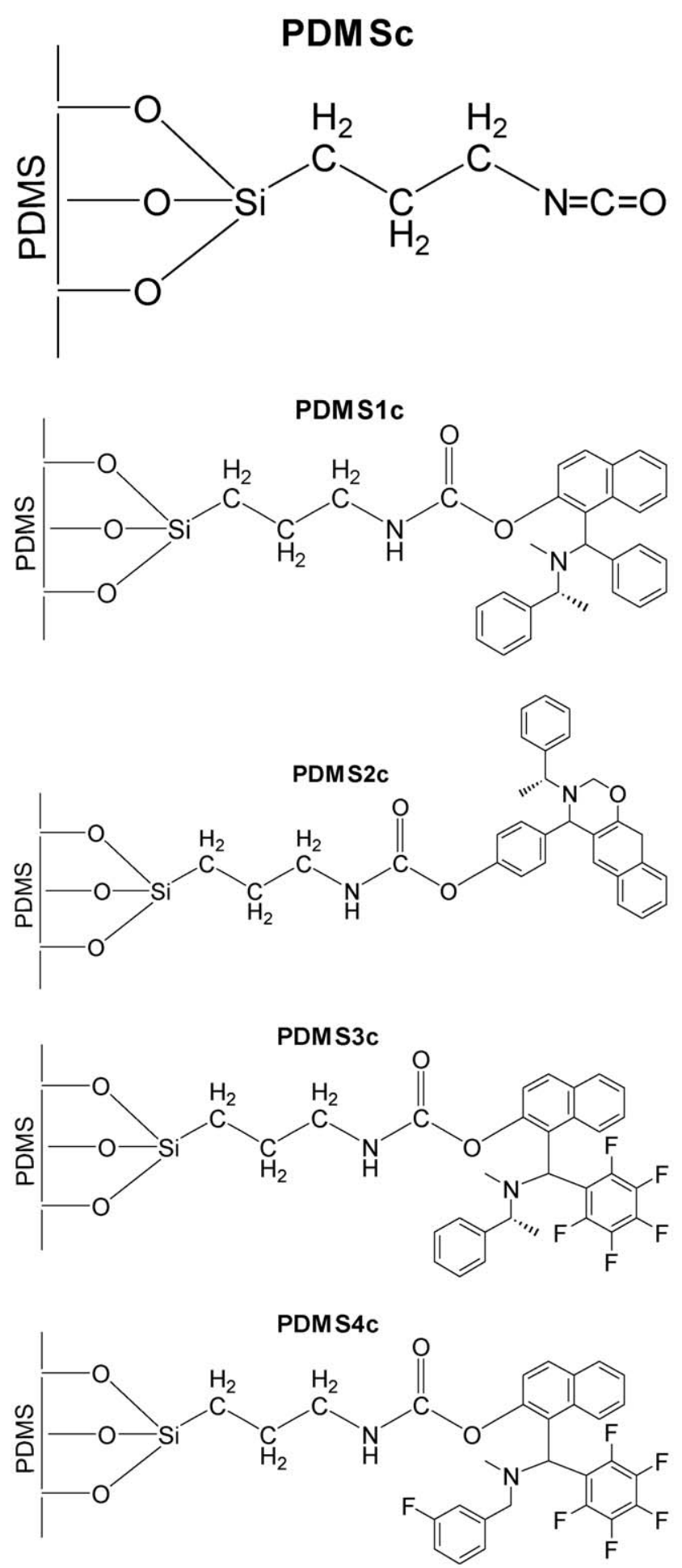

Chart 1. Structures of the surface-modified samples PDMSc and PDMS1c-PDMS4c.

naphthols, thus modulating microfluidic performances by using aminonaphtol-based structures having polar or non polar groups.

In particular, the introduction on PDMS surface of the fluorinecontaining structures $\mathbf{3 c}$ and $\mathbf{4 c}$ resulted in a increase in the filling time of the micro-channels by water fluid (111s and $142 \mathrm{~s}$ respectively), as shown in the experimental curves reported in Fig. 4 the highest value of contact angle $\left(123^{\circ}\right)$ was observed when the isocyanate $4 \mathrm{c}$, having six fluorine atoms as substituents on aromatic rings, was immobilized on PDMS surface. Therefore, the functionalization of PDMS walls with derivatives containing

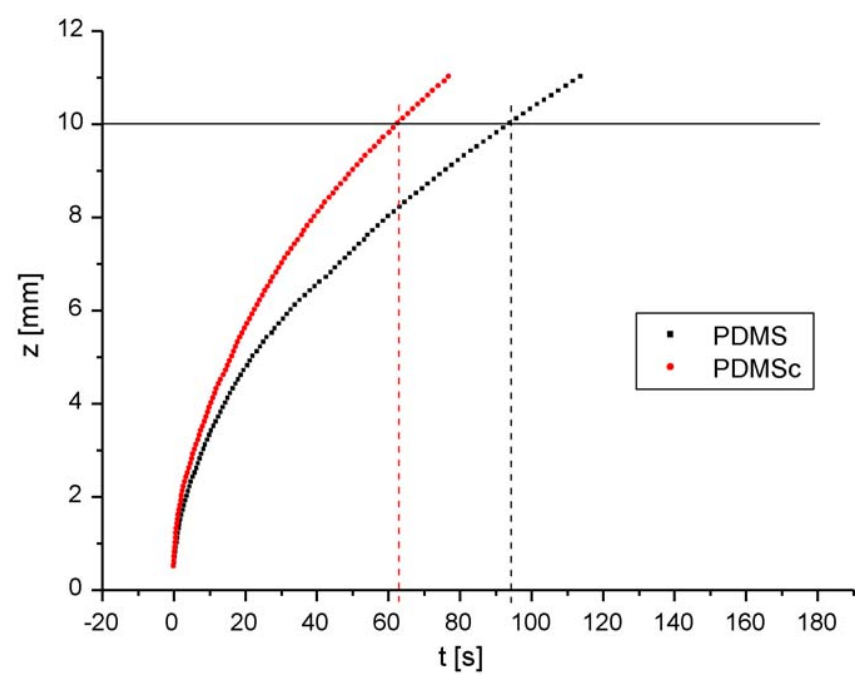

Fig. 3. Microfluidic tests for PDMS (black line) and PDMSc (red line) (10 mm channel length) (For interpretation of the references to color in this figure legend, the reader is referred to the web version of the article).

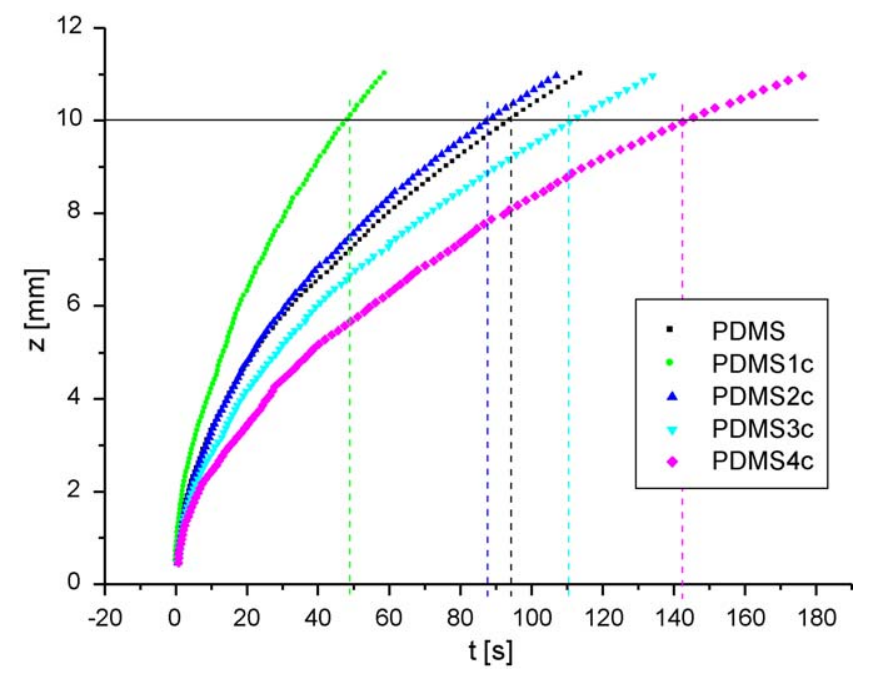

Fig. 4. Microfluidic tests for PDMS and PDMS1c-PDMS4c (10 mm channel length).

carbon-fluorine bonds [37,38] allows to obtain more hydrophobic surfaces, with a decreased capillarity-induced micro-channel filling and reduced chemical and physical interactions with aqueous medium. Furthermore, the low polarity of C-F bonds allow to minimize the surface free energy.

In summary, a simple and versatile process allows us to obtain differently substituted aminonaphthols, able to influence microfluidic performances depending on the hydrophilic or hydrophobic nature of the resulting structures. Contact angle measurements, reported in Table 1 , represent a useful indicator of surface characteristics and of the efficiency of surface treatments performed on PDMS flats.

Furthermore, for each PDMS functionalization, the agreement between experimental microfluidic results and the ones obtained from contact angle measurements was evaluated. To this purpose, the coefficient $b_{\mathrm{CA}}$ (Eq. (4) in theoretical model), which only depends on functionalized PDMS contact angle values (being $\theta_{\mathrm{Si}}=27.9^{\circ}$ ), was compared with $b_{\mu \mathrm{F}}$ (Eq. (3) in theoretical model), evaluated by a non-linear regression fit of the experimental $(t, z)$ curves.

First of all, the two coefficients of untreated PDMS have been compared: $b_{\text {CA_PDMS }}(1.71)$ resulted higher than $b_{\mu \mathrm{F} \_ \text {PDMS }}(1.003)$, 
Table 1

Contact angles, fill time values and fill time ratio with respect to untreated PDMS for PDMS, PDMSc, PDMS1c-PDMS4c.

\begin{tabular}{llll}
\hline Sample & CA & Fill time $(\mathrm{s})$ & Fill time ratio \\
\hline PDMS & $109.1^{\circ} \pm 1.21^{\circ}$ & 94 & 1.00 \\
PDMSc & $83.3^{\circ} \pm 1.60^{\circ}$ & 62 & 0.66 \\
PDMS1c & $79.3^{\circ} \pm 1.36^{\circ}$ & 49 & 0.52 \\
PDMS2c & $94.2^{\circ} \pm 1.66^{\circ}$ & 87 & 0.93 \\
PDMS3c & $116.2^{\circ} \pm 0.73^{\circ}$ & 111 & 1.18 \\
PDMS4c & $122.7^{\circ} \pm 1.80^{\circ}$ & 142 & 1.51 \\
\hline
\end{tabular}

Table 2

$b$ values for PDMS, PDMSc, PDMS1c-PDMS4c.

\begin{tabular}{llll}
\hline & $b_{\mathrm{CA}}\left(\mathrm{mm} / \mathrm{s}^{0.5}\right)$ & $b_{\mu F}\left(\mathrm{~mm} / \mathrm{s}^{0.5}\right)$ & $b_{\text {CA_cor }}\left(\mathrm{mm} / \mathrm{s}^{0.5}\right)$ \\
\hline PDMS & 1.71 & 1.00 & 1.00 \\
PDMSc & 2.34 & 1.26 & 1.37 \\
PDMS1c & 2.42 & 1.33 & 1.42 \\
PDMS2c & 2.08 & 1.06 & 1.22 \\
PDMS3c & 1.45 & 0.92 & 0.85 \\
PDMS4c & 1.26 & 0.81 & 0.74 \\
\hline
\end{tabular}

thus confirming what described by Delamarche et al. about the $40 \%$ reduction in velocity of the liquid in closed channels compared to their open counterparts [5]. To evaluate the presence of features not considered in the theoretical model and/or due to experimental measurements, it was calculated an empirical corrective factor $c=b_{\mu \mathrm{F}-\mathrm{PDMS}} / b_{\mathrm{CA}-\mathrm{PDMS}}$ approximate to 0.586 . In fact, for what concerns untreated PDMS, it is obvious that, unlike modified PDMS, the disagreement between $b_{\mathrm{CA}}$ and $b_{\mu \mathrm{F}}$ values can not depend on the surface functionalization process neither on the resulting modifiers immobilized surface density (the number of immobilized molecules in a unit surface).

In light of these considerations, for each functionalization, the term $b_{\text {CA cor }}$ was introduced (see Table 2 ) as result of the product of the corrective factor $c$ and $b_{\mathrm{CA}}$ values.

In particular, the introduction of the parameter $b_{\text {CA_cor }}$ remarked how inhomogeneities, impurities and changes in the wettability of modified microfluidic channels could provide further limits in real cases. In fact, as reported in Table 2, for hydrophobic surfaces (PDMS3c-PDMS4c), $b_{\text {CA_cor }}$ (which take into account of the corrective term $c=b_{\mu \mathrm{F}} / b_{\mathrm{CA}}$ for untreated PDMS), are slightly lower than the corresponding $b_{\mu \mathrm{F}}$ values thus suggesting that the slow filling of micro-channels is influenced by surface inhomogeneities coming from the functionalization process (the presence of not functionalized PDMS portions slightly increases $b_{\mu \mathrm{F}}$ value); similarly, $b_{\mathrm{CA} \text { _cor }}$ values for PDMS1c-PDMS2c are slightly higher than the corresponding $b_{\mu \mathrm{F}}$, since experimental $b_{\mu \mathrm{F}}$ values take into account the effect of the linked hydrophilic molecules but also the influence of not modified PDMS (Table 2).

Anyway, a relative comparison between the surface properties of functionalized PDMS samples, PDMSc-PDMS4c, is possible and the influence of the PDMS surface derivatizations by aminonaphtol-based isocyanates $\mathbf{1 c}-\mathbf{4 c}$ on micro-channel filling performances by water fluid can be evaluated.

\section{Conclusion}

An approach for modulating micro-channel filling rate through suitable chemical modifications of PDMS walls is reported. It involves a straightforward and versatile synthetic procedure that supplies a library of hydrophilic and hydrophobic aminonaphthols, depending on the substituents on aromatic rings. The functionalization from liquid phase of PDMS replicas, involving a covalent grafting of the above mentioned derivatives to activated PDMS surface, allows to modify microfluidic motion of water in rectangular capillaries: the filling rate of fluidic channels by water fluid increases upon customizing PDMS walls with more hydrophilic structures (PDMSc, PDMS1c-PDMS2c), while decreases upon covering PDMS with more hydrophobic molecules containing a series of $\mathrm{C}-\mathrm{F}$ bonds (PDMS3c-PDMS4c), thus suggesting a reduced chemical and physical interaction of micro-channel walls with aqueous medium. Furthermore, contact angle values evidence how wettability could be modulated depending on the different surface modifier, with the fluorinated aminonaphthols fuctionalized PDMS exhibiting the higher contact angles.

Finally, the functionalization process proposed in this paper offers the opportunity to develop systems where surface wettability have to be precisely and reproducibly adjusted and where a selective patterning of biomolecules from an aqueous medium could be realized through an anisotropic modification of PDMS walls.

\section{Experimental}

\subsection{General}

All experiments were carried out under ambient laboratory conditions (20-25 ${ }^{\circ} \mathrm{C}$ and $40-45 \%$ humidity).

Contact angle of liquids was measured on a Rame-Hart Model 100 goniometer (Dataphysics OCA 20) at room temperature and ambient humidity. The filling flow was followed in real time by an optical microscope.

Mass spectrometry analyses were carried out using an Agilent technologies HPLC mass spectrometer (1100 Series) equipped with an Electrospray (ESI) and an APCI (Atmospheric Pressure Chemical Ionization) interfaces. FT-IR spectra were recorded on a JASCO FTIR 660Plus spectrometer, in ATR (Attenuated Total Reflectance) mode. ${ }^{1} \mathrm{H}$ NMR spectra were recorded on a Bruker Avance 400 at room temperature and chemical shifts are reported relative to tetramethylsilane.

\subsection{Synthesis of chemical modifiers}

\subsubsection{Preparation of compounds $1-4$}

To an ethanol solution of 2-naphthol ( $10 \mathrm{mmol}, 1.24 \mathrm{~g}$ in $5 \mathrm{ml}$ ), an excess of aldehyde (14 mmol) and an equimolar amount of amine $(10 \mathrm{mmol}, 1.21 \mathrm{~g}$ ) was added for obtaining the amononaphthols 1-2; the synthesis of the fluorinated aminonaphthols 34 was carried out by adding a substoichiometric amount of amine $(8.5 \mathrm{mmol})$. Then the mixtures were stirred at $50{ }^{\circ} \mathrm{C}$ for six days and the crude products crystallized from ethanol solution.

\subsubsection{Preparation of compounds $1 a-4 a$}

To an ethanol solution of 1-4 (10 mmol in $25 \mathrm{ml})$, paraformaldehyde ( $50 \mathrm{mmol}, 1.50 \mathrm{~g}$ ) was added. The mixture was stirred at $50{ }^{\circ} \mathrm{C}$ for $4 \mathrm{~h}$. Then the crude product was centrifuged to remove the excess of paraformaldhyde and the liquid phase concentrated under reduced pressure.

\subsubsection{Preparation of compounds $1 b, 3 b-4 b$}

To a THF solution of 1a, 3a-4a $(10 \mathrm{mmol}$ in $40 \mathrm{ml}), \mathrm{NaBH}_{4}$ (40 mmol, $1.51 \mathrm{~g}$ ) was added. Subsequently a solution of TFA $(10 \mathrm{ml})$ in THF $(60 \mathrm{ml})$ was added dropwise and the resulting mixture stirred at $65{ }^{\circ} \mathrm{C}$ for $6 \mathrm{~h}$. After acid workup, the crude product was dissolved in diethyl ether, the precipitate removed by centrifugation and the liquid phase concentrated under reduced pressure.

\subsubsection{Preparation of compounds 1c-4c}

Under nitrogen atmosphere, 3-(triethoxysilylpropyl-isocyanate) (11 mmol, $2.72 \mathrm{~g}$ ) was added dropwise to a solution of $\mathbf{1 b}$, 
2a, 3b-4b $(10 \mathrm{mmol})$ in dichloromethane $(12.5 \mathrm{ml})$, in presence of triethylamine $(33 \mathrm{mmol}, 1.82 \mathrm{~g}, 2.5 \mathrm{ml}$ ). The mixture was stirred at room temperature for $8 \mathrm{~h}$ thus obtaining the surface modifiers 1c-4c. Compounds 1c-4c have been purified by crystallization from dichloromethane-hexane mixture: to a dichloromethane solution of compound $\mathbf{1 c}-\mathbf{4 c}$, hexane was added dropwise under stirring, until precipitation of solid was observed. The solid was then filtered and dried. The obtained molecules were characterized by LC-MS, FT-IR and ${ }^{1} \mathrm{H}$ NMR spectroscopies (Table 3).

\subsection{Preparation of masters}

Photolithography was employed to fabricate Si substrates for PDMS replication.

A standard photoresist (SU-8-2000, MicroChem) [39] was spun on Si substrate, exposed to UV radiation and developed. Then the substrate was etched using $\mathrm{NH}_{4} \mathrm{~F} / \mathrm{HF} / \mathrm{H}_{2} \mathrm{O}$ and the obtained mask employed to etch silicon using a $6.0 \mathrm{M} \mathrm{H}_{2} \mathrm{O} /{ }^{\mathrm{i}} \mathrm{PrOH}$ solution of $\mathrm{KOH}$ at $80{ }^{\circ} \mathrm{C}$.

A ruler was integrated in the masters, side by side with the channels, to exactly determine by optical microscopy the length covered by the water fluid during the filling process.

\subsection{Preparation of PDMS samples}

An elastomeric mold was fabricated from poly(dimethylsiloxane) (PDMS, Sylgard 184, Dow Corning, Midland, MI) by casting PDMS against a master (prepared as previously reported) that contained a three-dimensional relief pattern to be replicated. The master was used a number of times to fabricate multiple copies of the elastomeric mold.

Sylgard 184 silicone elastomer was supplied as a two-part liquid component kit comprised of base and curing agent. PDMS samples were prepared mixing the silicone base and its curing agent (containing cross-linker and catalytic amount of a $\mathrm{Pt}$ catalyst) in a 10:1 weight ratio, pouring onto $\mathrm{Si}$ masters and allowing to stand for $30 \mathrm{~s}$, to favour the emersion of trapped air bubbles. The degassed mixture was cured at $140{ }^{\circ} \mathrm{C}$ for $15 \mathrm{~min}$ and then gently peeled away.

The PDMS mold was made sufficiently thin (approximately $1 \mathrm{~mm}$ in thickness) to follow the imbibition front when it advances in microcapillaries during microfluidic experiments. A typical size of the mold is $2.0 \mathrm{~cm} \times 1,0 \mathrm{~cm}$ and the length of the channels in the mold $\sim 1.5 \mathrm{~cm}$. Only one end of the channels in the mold was open to allow a liquid to enter. The high solubility of such gases as $\mathrm{N}_{2}$ and $\mathrm{O}_{2}$ in PDMS makes the term of the internal pressure $\left(\Delta \mathrm{p}_{\mathrm{int}}\right)$, due to

Table 3

Spectroscopic data of compounds $\mathbf{2 a}, \mathbf{1 b}, \mathbf{3 b}-\mathbf{4 b}, \mathbf{1 c}-\mathbf{4 c}$

\begin{tabular}{|c|c|c|c|c|}
\hline Compound & Yield (\%) & LC-MS $(m / z)$ & FT-IR $\left(\mathrm{cm}^{-1}\right)$ & ${ }^{1} \mathrm{H}$ NMR $\left(400 \mathrm{MHz}, \mathrm{CDCl}_{3}\right)$ \\
\hline $\mathbf{2 a}$ & 79 & $m / z=382[\mathrm{M}+1]^{+}$ & $\begin{array}{l}3333,3060,2974,2926,2898,1681 \\
1622,1598,1514,1485,1467,1453 \\
1436,1402,1353,1263,1231,1154 \\
1071,1018,998,860\end{array}$ & $\begin{array}{l}\delta=7.67-7.05(\mathrm{Ar}, 12 \mathrm{H}), 6.92(\mathrm{~d}, \mathrm{Ar}, 1 \mathrm{H}), 6.68(\mathrm{~d}, \mathrm{Ar}, 2 \mathrm{H}), 5.28 \\
\left(\mathrm{~s}, \mathrm{HOC}_{6} \mathrm{H}_{4} \mathrm{CH}-\mathrm{N}-, 1 \mathrm{H}\right), 5.18\left(\mathrm{dd},-\mathrm{N}-\mathrm{CH}_{2}-\mathrm{O}-, 2 \mathrm{H}, J=10.8 \mathrm{~Hz}\right) \\
4.98\left(\mathrm{dd}, \mathrm{N}-\mathrm{CH}_{2}-\mathrm{O}-, 2 \mathrm{H}, J=10.8 \mathrm{~Hz}\right), 4.09\left(\mathrm{q}, \mathrm{CH}_{3}-\mathrm{CH}-\mathrm{N}-, 1 \mathrm{H},\right. \\
J=6.6 \mathrm{~Hz}), 1.57\left(\mathrm{~d}, \mathrm{CH}_{3}-\mathrm{CH}-\mathrm{N}-, 3 \mathrm{H}, J=6.6 \mathrm{~Hz}\right) \mathrm{ppm}\end{array}$ \\
\hline 1b & 82 & $m / z=368[\mathrm{M}+1]^{+}$ & $\begin{array}{l}3064,2926,2853,1674,1624,1518 \\
1456,1438,1338,1269,1241,1200 \\
1136,973,900,834\end{array}$ & $\begin{array}{l}\delta=7.77-7.05(\mathrm{Ar}, 15 \mathrm{H}), 6.85(\mathrm{Ar}, \mathrm{d}, 1 \mathrm{H}), 5.29\left(\mathrm{~s}, \mathrm{Ar}^{1} \mathrm{Ar}^{2}-\mathrm{CH}-\mathrm{N}, 1 \mathrm{H}\right) \\
4.22\left(\mathrm{q}, \mathrm{Ar}^{1} \mathrm{Me}-\mathrm{CH}-\mathrm{N}, 1 \mathrm{H}, J=6.6 \mathrm{~Hz}\right), 2.13\left(\mathrm{~s}, \mathrm{CH}_{3}-\mathrm{N}, 3 \mathrm{H}\right), \\
1.59\left(\mathrm{~d}, \mathrm{CH}_{3}-\mathrm{CH}-\mathrm{N}, 3 \mathrm{H}, J=6.6 \mathrm{~Hz}\right) \mathrm{ppm}\end{array}$ \\
\hline 3b & 76 & $m / z=458[\mathrm{M}+1]^{+}$ & $\begin{array}{l}3330,1674,1627,1601,1518,1499 \\
1465,1436,1401,1355,1304,1274 \\
1232,1206,1141,1122,1018,992,928\end{array}$ & $\begin{array}{l}\delta=7.82-7.07(\mathrm{~m}, \mathrm{Ar}, 10 \mathrm{H}), 6.87(\mathrm{Ar}, \mathrm{d}, 1 \mathrm{H}), 5.31(\mathrm{~s}, \mathrm{Ar}-\mathrm{CH}-\mathrm{N}-, 1 \mathrm{H}), \\
4.18\left(\mathrm{q}, \mathrm{CH}_{3}-\mathrm{CH}-\mathrm{N}-, 1 \mathrm{H}, J=6.6 \mathrm{~Hz}\right), 2.32\left(\mathrm{~s}, \mathrm{CH}_{3}-\mathrm{N}-, 3 \mathrm{H}\right), \\
1.59\left(\mathrm{~d}, \mathrm{CH}_{3}-\mathrm{CH}-\mathrm{N}-, 3 \mathrm{H}, J=6.6 \mathrm{~Hz}\right) \mathrm{ppm} .\end{array}$ \\
\hline $4 b$ & 89 & $m / z=462[\mathrm{M}+1]^{+}$ & $\begin{array}{l}3330,2954,1655,1625,1591,1519 \\
1498,1467,1436,1401,1365,1306 \\
1252,1232,1141,1122,1076,1018,995\end{array}$ & $\begin{array}{l}\delta=7.88-7.08(\mathrm{Ar}, 6 \mathrm{H}), 6.91(\mathrm{Ar}, \mathrm{d}, 1 \mathrm{H}), 6.84-6.77(\mathrm{Ar}, 3 \mathrm{H}) \\
5.30(\mathrm{~s}, \mathrm{Ar}-\mathrm{CH}-\mathrm{N}-, 1 \mathrm{H}), 3.72\left(\mathrm{~s}, m-\mathrm{FC}_{6} \mathrm{H}_{4}-\mathrm{CH}_{2}-\mathrm{N}-, 2 \mathrm{H}\right) \\
2.33\left(\mathrm{~s}, \mathrm{CH}_{3}-\mathrm{N}-, 3 \mathrm{H}\right) \mathrm{ppm}\end{array}$ \\
\hline 1c & 81 & $m / z=616[\mathrm{M}+1]^{+}$ & $\begin{array}{l}2976,2928,2887,1690,1564,1478 \\
1445,1391,1251,1200,1168,1070,956\end{array}$ & $\begin{array}{l}\delta=7.97-7.07(\mathrm{Ar}, 15 \mathrm{H}), 6.85(\mathrm{Ar}, \mathrm{d}, 1 \mathrm{H}), 5.26\left(\mathrm{~s}, \mathrm{Ar}^{1} \mathrm{Ar}^{2}-\mathrm{CH}-\mathrm{N},\right. \\
1 \mathrm{H}), 4.18\left(\mathrm{q}, \mathrm{Ar}^{1} \mathrm{Me}-\mathrm{CH}-\mathrm{N}, 1 \mathrm{H}, J=6.6 \mathrm{~Hz}\right), 3.79\left(\mathrm{q},-\mathrm{OCH}_{2}-\mathrm{CH}_{3},\right. \\
6 \mathrm{H}, J=7.00 \mathrm{~Hz}), 3.19\left(\mathrm{t}, \mathrm{NH}-\mathrm{CH}_{2}-\mathrm{CH}_{2}-, 2 \mathrm{H}, J=6.5 \mathrm{~Hz}\right) \\
2.50\left(\mathrm{~s}, \mathrm{CH}_{3}-\mathrm{N}, 3 \mathrm{H}\right), 1.69\left(-\mathrm{NHCH}_{2} \mathrm{CH}_{2} \mathrm{CH}_{2} \mathrm{Si}-, 2 \mathrm{H}, J=7.00 \mathrm{~Hz}\right) \\
1.60\left(\mathrm{~d}, \mathrm{CH}_{3}-\mathrm{CH}-\mathrm{N}, 3 \mathrm{H}, J=6.6 \mathrm{~Hz}\right), 1.33\left(\mathrm{t},-\mathrm{OCH}_{2}-\mathrm{CH}_{3},\right. \\
9 \mathrm{H}, J=7.00 \mathrm{~Hz}), 0.61\left(\mathrm{t},-\mathrm{CH}_{2} \mathrm{Si}, 2 \mathrm{H}, J=8.1 \mathrm{~Hz}\right) \mathrm{ppm}\end{array}$ \\
\hline 2c & 80 & $m / z=630[\mathrm{M}+1]^{+}$ & $\begin{array}{l}2973,2926,2885,2734,1724,1624 \\
1600,1514,1482,1441,1389,1210 \\
1165,1077,950,864\end{array}$ & $\begin{array}{l}\delta=7.78-6.91(\mathrm{Ar}, 15 \mathrm{H}), 5.28\left(\mathrm{~s},-\mathrm{OC}_{6} \mathrm{H}_{4} \mathrm{CH}-\mathrm{N}-, 1 \mathrm{H}\right), 5.18 \\
\left(\mathrm{dd},-\mathrm{N}-\mathrm{CH}_{2}-\mathrm{O}-, 2 \mathrm{H}, J=10.8 \mathrm{~Hz}\right), 4.98\left(\mathrm{dd}, \mathrm{N}-\mathrm{CH}_{2}-\mathrm{O}-, 2 \mathrm{H},\right. \\
J=10.8 \mathrm{~Hz}), 4.10\left(\mathrm{q}, \mathrm{CH}_{3}-\mathrm{CH}-\mathrm{N}-, 1 \mathrm{H}, J=6.6 \mathrm{~Hz}\right), 3.82 \\
\left(\mathrm{q}, \mathrm{O}-\mathrm{CH}_{2}-\mathrm{CH}_{3}, 6 \mathrm{H}, J=7.00 \mathrm{~Hz}\right), 3.25\left(\mathrm{t}, \mathrm{NH}-\mathrm{CH}_{2}-\mathrm{CH}_{2}-\right. \\
2 \mathrm{H}, J=6.5 \mathrm{~Hz}), 1.69\left(\mathrm{~m},-\mathrm{NH}-\mathrm{CH}_{2}-\mathrm{CH}_{2}-\mathrm{CH}_{2}-\mathrm{Si}-, 2 \mathrm{H},\right. \\
J=7.00 \mathrm{~Hz}), 1.54\left(\mathrm{~s}, \mathrm{CH}_{3}-\mathrm{CH}-\mathrm{N}, 3 \mathrm{H}, J=6.6 \mathrm{~Hz}\right), 1.26 \\
\left(\mathrm{t},-\mathrm{OCH}_{2} \mathrm{CH}_{3}, 9 \mathrm{H}, \mathrm{J}=7.00 \mathrm{~Hz}\right), 0.64\left(\mathrm{t},-\mathrm{CH}_{2} \mathrm{Si}-\right. \\
2 \mathrm{H}, J=8.1 \mathrm{~Hz}) \mathrm{ppm}\end{array}$ \\
\hline $3 c$ & 66 & $m / z=705[\mathrm{M}+1]^{+}$ & $\begin{array}{l}2978,1695,1627,1519,1505,1466 \\
1437,1397,1365,1305,1276,1233 \\
1203,1160,1121,1075,1018,993\end{array}$ & $\begin{array}{l}\delta=7.73-7.09(\mathrm{~m}, \mathrm{Ar}, 10 \mathrm{H}), 6.89(\mathrm{Ar}, \mathrm{d}, 1 \mathrm{H}), 5.32(\mathrm{~s}, \mathrm{Ar}-\mathrm{CH}-\mathrm{N}- \\
1 \mathrm{H}), 4.15\left(\mathrm{q}, \mathrm{Ar}^{1} \mathrm{Me}-\mathrm{CH}-\mathrm{N}, 1 \mathrm{H}, J=6.6 \mathrm{~Hz}\right), 3.82\left(\mathrm{q},-\mathrm{OCH}_{2}-\mathrm{CH}_{3},\right. \\
6 \mathrm{H}, J=7.00 \mathrm{~Hz}), 3.19\left(\mathrm{~m},-\mathrm{NH}-\mathrm{CH}_{2}-, 2 \mathrm{H}, J=6.5 \mathrm{~Hz}\right) \\
2.22\left(\mathrm{~s}, \mathrm{CH}_{3}-\mathrm{N}-, 3 \mathrm{H}\right), 1.67\left(\mathrm{~m},-\mathrm{NHCH}_{2} \mathrm{CH}_{2} \mathrm{H}_{2} \mathrm{Si}-\right. \\
2 \mathrm{H}, J=7.00 \mathrm{~Hz}), 1.58\left(\mathrm{~d}, \mathrm{CH}_{3}-\mathrm{CH}-\mathrm{N}, 3 \mathrm{H}, J=6.6 \mathrm{~Hz}\right) \\
1.32\left(\mathrm{t},-\mathrm{OCH}_{2} \mathrm{CH}_{3}, 9 \mathrm{H}, J=7.00 \mathrm{~Hz}\right), 0.69\left(\mathrm{t},-\mathrm{CH}_{2} \mathrm{Si}, 2 \mathrm{H}\right. \\
J=8.1 \mathrm{~Hz}) \mathrm{ppm}\end{array}$ \\
\hline $4 c$ & 72 & $m / z=709[\mathrm{M}+1]^{+}$ & $\begin{array}{l}2985,2937,1696,1655,1625,1591 \\
1520,1500,1466,1437,1401,1366 \\
1306,1251,1198,1123,1019,995\end{array}$ & $\begin{array}{l}\delta=7.90-7.09(\mathrm{~m}, \mathrm{Ar}, 6 \mathrm{H}), 6.92(\mathrm{Ar}, \mathrm{d}, 1 \mathrm{H}), 6.84-6.78 \\
(\mathrm{Ar}, 3 \mathrm{H}), 5.37(\mathrm{~s}, \mathrm{Ar}-\mathrm{CHN}, 1 \mathrm{H}), 3.79\left(\mathrm{q}, \mathrm{OCH}_{2} \mathrm{CH}_{3}, 6 \mathrm{H}, J=7.00 \mathrm{~Hz}\right) \\
3.70\left(\mathrm{~s}, m-\mathrm{FC}_{6} \mathrm{H}_{4}-\mathrm{CH}_{2}-\mathrm{N}-, 2 \mathrm{H}\right), 3.17\left(\mathrm{~m},-\mathrm{NH}^{-} \mathrm{CH}_{2}-, 2 \mathrm{H}\right. \\
J=6.5 \mathrm{~Hz}), 2.22\left(\mathrm{~s}, \mathrm{CH}_{3}-\mathrm{N}-, 3 \mathrm{H}\right), 1.67\left(\mathrm{~m}, \mathrm{CH}_{2} \mathrm{CH}_{2} \mathrm{CH}_{2}, 2 \mathrm{H}\right. \\
J=7.00 \mathrm{~Hz}), 1.40\left(\mathrm{t}, \mathrm{OCH}_{2} \mathrm{CH}_{3}, 9 \mathrm{H}, J=7.00 \mathrm{~Hz}\right), 0.66 \\
\left(\mathrm{t},-\mathrm{CH}_{2} \mathrm{Si}, 2 \mathrm{H}, J=8.1 \mathrm{~Hz}\right) \mathrm{ppm}\end{array}$ \\
\hline
\end{tabular}




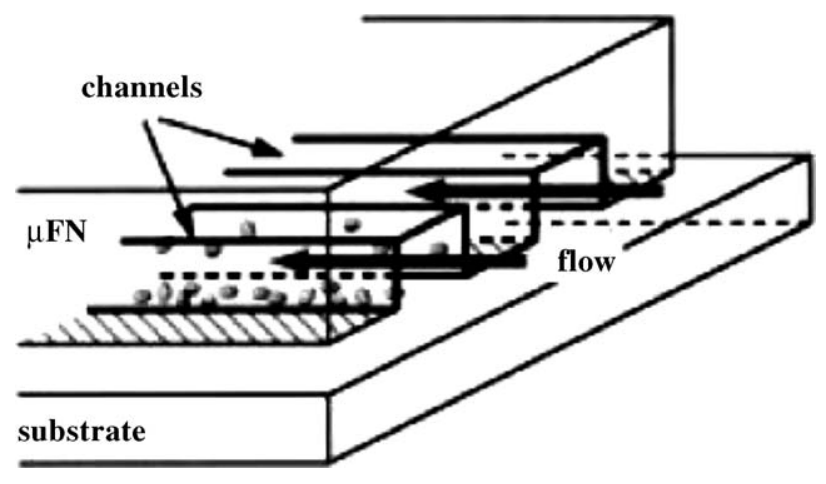

Fig. 5. A scheme for a microfluidic network useful for the capillary motion of water.

air column trapped inside the micro-channel, relatively unimportant: channels open at only one end are completely filled even if the velocity of the liquid is typically around $40 \%$ slower in these closed channels compared to their open counterparts [5].

When the elastomeric mold was placed on Si substrate, the compliant nature of PDMS allowed close and uninterrupted contact between the mold and the substrate surface, thus forming an array (or a network) of channels. These channels were accessible to a fluid from the open end. When a drop $(\sim 0.2-$ $0.5 \mathrm{ml}$ ) of a water was placed at the end of the channels, the liquid filled the channels by capillary action (Fig. 5).

\subsection{Functionalization of PDMS surface}

PDMS was activated by exposure to $\mathrm{O}_{2}$ plasma generated in a RIE IONVAC inductively coupled (ICP) plasma reactor (PGF $600 \mathrm{RF}$ HUTTER) for $2 \mathrm{~min}$ (optimized plasma conditions: $50 \mathrm{~W}$, 70 mTorr). Soon after, the organic modifiers (c and 1c-4c), solved in a $0.5 \mathrm{M}$ THF solution, were immobilized to activated PDMS (PDMS-OH), through a functionalization from liquid phase.

PDMS replicas and flats (no patterned surfaces) were modified: the first were employed in microfluidic tests, the second in contact angle measurements. In particular, each activated PDMS replica was put on a glass substrate with its relief parts perfectly adherent to a glass surface, then a few drops of the solution were introduced by capillarity into the empty rectangular micro-channels. In this manner, relief parts kept their adherence and conformal contact properties, just only the inner walls of the micro-channels coming to be modified.

The process continued for $8 \mathrm{~h}$, then PDMS replicas were thoroughly rinsed under ultrasonication at room temperature, once in ethanol, three times in bidistilled water for $5 \mathrm{~min}$.

\section{References}

[1] Y.N. Xia, G.M. Whitesides, Angew. Chem., Int. Ed. 37 (1998) 551-575.

[2] E. Kim, Y.N. Xia, G.M. Whitesides, Nature 376 (1995) 581-584.

[3] E. Kim, G.M. Whitesides, J. Phys. Chem. 101 (1997) 855-863.
[4] E. Delamarche, A. Bernard, H. Schmid, B. Michel, H. Biebuyck, Science 276 (1997) 779-781.

[5] E. Delamarche, A. Bernard, H. Schmid, A. Bietsch, B. Michel, H. Biebuyck, J. Am. Chem. Soc. 120 (1998) 500-508.

[6] A. Papra, A. Bernard, D. Juncker, N.B. Larsen, B. Michel, E. Delamarche, Langmuir 17 (2001) 4090-4095.

[7] I. Caelen, A. Bernard, D. Juncker, B. Michel, H. Heinzelmann, E. Delamarche, Langmuir 16 (2000) 9125-9130.

[8] A. Bernard, B. Michel, E. Delamarche, Anal. Chem. 73 (2001) 8-12.

[9] A. Han, G. Mondin, N.G. Hegelback, N.F. de Rooij, U. Staufer, J. Colloid Interface Sci. 293 (2006) 151-157.

[10] H. Makamba, J.H. Kim, K. Lim, N. Park, J.H. Hahn, Electrophoresis 24 (2003) 36073619.

[11] S. Hu, X. Ren, N. Bachman, C.E. Sims, G.P. Li, N. Allbritton, Anal. Chem. 74 (2002) 4117-4123.

[12] S. Hu, X. Ren, N. Bachman, C.E. Sims, G.P. Li, N. Allbritton, Langmuir 20 (2004) 5569-5574.

[13] S. Hu, X. Ren, N. Bachman, C.E. Sims, G.P. Li, N. Allbritton, Anal. Chem. 76 (2004) 1865-1870.

[14] D. Bodas, C.K. Malek, Sens. Actuators B 120 (2007) 719-723.

[15] D. Bodas, C.K. Malek, Microelectr. Eng. 83 (2006) 1277-1279.

[16] S. Sugiura, J.-I. Edahiro, K. Sumaru, T. Kanamori, Colloids Surf. B: Biointerfaces 63 (2008) 301-305.

[17] I. Wang, H.-H. Lai, M. Bachman, C.E. Sims, G.P. Li, L. Allbritton, Anal. Chem. 77 (2005) 7539-7546.

[18] N. Patrito, C. McCague, S. Chiang, P.R. Norton, N.O. Petersen, Langmuir 22 (2006) 3453-3455.

[19] C. Donzel, M. Geissler, A. Bernard, H. Wolf, B. Michel, J. Hilborn, E. Delamarche, Adv. Mater. 13 (2001) 1164-1167.

[20] D. Xiao, H. Zhang, M. Wirth, Langmuir 18 (2002) 9971-9976.

[21] W. Hellmich, J. Regtmeier, T.T. Duong, R. Ros, D. Anselmetti, A. Ros, Langmuir 21 (2005) 7551-7557.

[22] H. Chen, Z. Zhang, Y. Chen, M.A. Brook, H. Sheardown, Biomaterials 26 (2005) 2391-2399.

[23] G. Sui, J. Wang, C.-C. Lee, W. Lu, S.P. Lee, J.W. Leyton, A.M. Wu, H.-R. Tseng, Anal. Chem. 78 (2006) 5543-5551.

[24] J.H. Silver, J.C. Lin, F. Lim, V.A. Tegoulia, M.H. Chaudhury, S.L. Cooper, Biomaterials 20 (1999) 1533-1543.

[25] K.C. Popat, T.A. Desai, Biosens. Bioelectron. 19 (2004) 1037-1044.

[26] H. Ye, Z. Gu, D.H. Gracias, Langmuir 22 (2006) 1863-1868.

[27] A. Muck, A. Svatoš, Talanta 74 (2007) 333-341.

[28] R.A. Lawton, C.R. Price, A.F. Runge, W.J. Doherty III, S. Saavedra, Colloids Surf. A: Physicochem. Eng. Aspects 253 (2005) 213-215.

[29] D. Kiaei, A.S. Hoffmann, B.D. Ratner, D.A. Horbett, J. Appl. Polym. Sci., Appl. Polym. Synth. 42 (1988) 269-283.

[30] C. Mao, Y. Qiu, H. Sang, H. Mei, A. Zhu, J. Shen, S. Lin, Adv. Colloids Interface Sci. 110 (2004) 5-17.

[31] C. Cardellicchio, G. Ciccarella, F. Naso, E. Schingaro, F. Scordari, Tetrahedron: Asymmetry 9 (1998) 3667-3675.

[32] C. Cardellicchio, G. Ciccarella, F. Naso, F. Perna, P. Tortorella, Tetrahedron 55 (1999) 14685-14692; C. Cardellicchio, G. Ciccarella, F. Naso, 2000, "Derivatives of 1 -( $\alpha$-aminobenzyl)-2-naphthol (Betti's base), processes for their preparation and their optical resolution, and their use as resolving agents and optically active ligands", MI98A000159, Consiglio Nazionale Delle Ricerche.(RM).

[33] Y. Dong, J. Sun, X. Wang, X. Xu, L. Cao, Y. Hu, Tetrahedron: Asymmetry 15 (2004) 1667-1672.

[34] (a) M. Betti, Gazz. Chim. Ital. 30 II (1900) 310-316;

(b) M. Betti, Gazz. Chim. Ital. 31 I (1901) 377-393;

(c) M. Betti, Gazz. Chim. Ital. 31 II (1901) 170-184;

(d) M. Betti, Gazz. Chim. Ital. 31 II (1901) 191-200.

[35] D. Liu, Q. Zhang, C. Da, Z. Xin, R. Wang, M.C.K. Choi, A.S.C. Chan, Org. Lett 3 (2001) 2733-2735.

[36] P. Hesemann, J.J.E. Moreau, Tetrahedron: Asymmetry 11 (2000) 2183-2194.

[37] T. Miyata, H. Yamada, T. Uragami, Macromolecules 34 (2001) 8026-8033.

[38] O. Garcia, R. Sastre, D. del Agua, A. Costela, I. Garcia-Moreno, Chem. Mater. 18 (2006) 601-602.

[39] The SU-8 process procedure we followed is reported in the manual from MicroChem Corp. Data sheets, SU-8 photoresist formulations 2-25. http:// www.microchem.com/products. 